\title{
Self- and maternal representations, relatedness patterns, and problem behavior in middle childhood
}

\author{
ARIELA WANIEL, ${ }^{a}$ AVI BESSER, ${ }^{b}$ AND BEATRIZ PRIEL ${ }^{a}$ \\ ${ }^{a}$ Ben-Gurion University of the Negev and ${ }^{b}$ Sapir Academic College
}

\begin{abstract}
The present study investigated the association between children's representations of their mothers' and teachers' reports of children's problem behavior. The research team conducted semistructured narrative interviews with a community sample of 203 Israeli 9- to 11-year-old children. Ten months later, researchers collected teachers' reports of children's internalizing and externalizing problems. This study investigated whether children's self-representation narratives and their maladaptive relatedness stances questionnaire scores mediated this association. Results indicated that children reporting benevolent representations of their mothers exhibited lower levels of problem behavior. More positive self-representations and lower levels of skewness in children's relatedness stances to their mothers both mediated this association. This article includes a discussion of these results in light of factors contributing to maladjustment in middle childhood.
\end{abstract}

Object relations and attachment theories suggest that internal representations or working models of the caregiver are related to competent adjustment by enabling the construction of a stable and positive self-perception and by molding adaptive patterns of interpersonal interaction with significant others (Greenberg \& Mitchell, 1983). These interpersonal patterns of relatedness are significant predictors of adjustment outcomes in infant and adult samples (Buist, Dekovilc, Meeus, \& Van-Aken,

Ariela Waniel, Department of Behavioral Sciences, BenGurion University of the Negev, Beer-Sheva, Israel; Avi Besser, Department of Behavioral Sciences, Sapir Academic College, D. N. Hof Ashkelon, Israel; Beatriz Priel, Department of Behavioral Sciences, Ben-Gurion University of the Negev, Beer-Sheva, Israel.

We based this article in part on Ariela Waniel's doctoral dissertation under the direction of Beatriz Priel. The Research Advisory Board of the International Psychoanalytical Association supported this research in part. We extend grateful thanks to the teachers and students who agreed to participate in this study.

Correspondence should be addressed to Beatriz Priel, Ben-Gurion University of the Negev, Department of Behavioral Sciences, Beer-Sheva 84105, Israel, e-mail: bpriel@bgu.ac.il.
2004; Fonagy \& Target, 1997; Hamilton, 2000). Less is known, however, about these associations in school-age children, who were the focus of the present investigation. In the present study, we were interested in targeting the association between school-age children's internal representation of mother, relatedness style to her, and maladaptive behavior. From a developmental standpoint, middle childhood is a period where children are beginning to represent objects cognitively at a more abstract level (Piaget, 1955, 1962) and their social interactions with significant others become more complex and intimate (Baldwin, Cole, \& Baldwin, 1982; Baumrind, 1989). These parallel processes have a direct bearing on the quality of children's internal model of the caregiver and their perception of their relationship with her.

\section{Children's object representations}

Object relations theories originated as an approach that centered on processes that constitute and mediate the individual's capacity for relating to others (e.g., Greenberg \& Mitchell, 
1983). Object relations are motivational structures that guide perception and affect the organization of past experience and expectations. These internalized representations include impressions of the relationships with parents and presumably influence processes of meaning attribution, encompassing interpersonal relationships, motivations, and attitudes. Parental representations constitute developing templates for the capacity for mutual, satisfying, and attuned patterns of relationships with others (Blatt, Auerbach, \& Levy, 1997). Representations tend to include conscious contents as well as organizational principles, which are less accessible to conscious thought (Bretherton, 1990; Levy, Blatt, \& Shaver, 1998). Furthermore, representations of significant others do not necessarily reflect real events but function as patterns of mental activation that might include defensive distortions (Bretherton \& Munholland, 1999).

Narrative techniques, based on open-ended responses to significant stimuli, try to address these unique characteristics of mental representations in their assessment procedure. One such measure, initially designed for adult and adolescent populations, is the Object Relations Inventory (ORI), a narrative technique for the assessment of qualitative and structural dimensions of object representations (Blatt, Chevron, Quinlan, Schaffer, \& Wein, 1992; Blatt, Wein, Chevron, \& Quinlan, 1979). This assessment technique is based on open narratives about parents or significant others. Blatt and colleagues first defined and assessed the basic dimensions of the ORI in adult clinical and nonclinical populations (Blatt, Wiseman, PrinceGibson, \& Gatt, 1991; Gruen \& Blatt, 1990) and then adapted the indices for use with children (Priel, Myodovnick, \& Rivlin-Beniaminy, 1995; Waniel, Besser, \& Priel, 2006).

The ORI narratives provide an individual's internal experience account of the parental figures. This narrative technique is designed for gaining insight into the subject's way of thinking about significant caregivers, in terms of the attributes associated with them, as well as the complex cognition involved in representing them. A major aspect of this technique is the differentiation made between content and structural aspects of mental repre- sentations, a procedure other researchers of child development follow (Shields, Ryan, \& Cicchetti, 2001). Whereas the qualitative dimension captures children's caretaking experiences and the affective tone of parentchild relationships, the structural dimension reflects the representation's basic cognitive organizing principles (Piaget, 1955, 1962; Werner, 1948). In children's descriptions of significant others, narrative content seems to capture perceptions of the parent's degree of benevolence, care, and supportive involvement (Shields et al., 2001; Westen et al., 1991), as well as the parent's degree of criticism and punitiveness (Westen et al., 1991). Narrative structural aspects include the complexity level through which the child perceives the parent (Bretherton, 1990; Main, Kaplan, \& Cassidy, 1985) as well as the description's degree of integration or coherence (Fonagy, 1994; Westen et al., 1991).

Empirical studies have found significant associations between dimensions of children's representations of the mother and aspects of children's personality and functioning (Avery \& Ryan, 1988; Priel et al., 1995). Specifically, these studies have found significant associations between the structural aspects of children's representations of the mother and children's cognitive development in normal populations (Avery \& Ryan, 1988; Waniel et al., 2006), as well as between content aspects of the maternal representation and measures of socioemotional adjustment in middle childhood (Priel, Kantor, \& Besser, 2000; Segal, Westen, Lohr, \& Silk, 1993; Westen et al., 1991). In the present study, we will focus on the qualitative or content attributes of the maternal representation because we are interested in exploring children's problem behaviors in the socioemotional domains (internalizing and externalizing symptoms) rather than their cognitive functioning. In addition, empirical research has shown substantial overlap between children's internal representations of mothers and fathers (Belsky \& Rovine, 1987; Fox, Kimmerly, \& Schafer, 1991; Steele, Steele, \& Fonagy, 1996; van IJzendoorn \& De Wolff, 1997), and therefore, in the present study, we will include only the subjects' maternal representations. 


\section{Children's skewed relatedness stances}

Attachment theory proposes processes through which experiences in the relationships with significant others are organized and modeled into internal schemas conceptualized as developmental structures that guide subsequent interpersonal perception and functioning. Bowlby (1969, 1973, 1980) proposed the concept of internal working models of attachment, which include the subject's memories, perceptions, and expectations in relation to significant others as helpful and effective in diminishing distress. Attachment theory defines secure attachment as the ability to use the caregiver not only for protection and closeness but also as a stable base from which to explore the environment and one's independent capabilities (Bowlby, 1969, 1973, 1980).

Children classified as having either an anxious-avoidant or an anxious-resistant (or ambivalent) attachment style do not exhibit the required balance between closeness and autonomy in their relationships with caregivers (Ainsworth, Blehar, Waters, \& Wall, 1978; Cassidy, Kirsh, Scolton, \& Parke, 1996). Children with an anxious-resistant (or ambivalent) style express powerful needs for closeness to the caregiver, which disrupt the child's adequate experiences in situations of separation and his or her ability to exercise autonomic skills. Children with an anxiousavoidant style express strong needs of detachment and distancing, which disrupt their ability to use the caregiver as a source of protection and a provider of emotional needs. Studies have found both avoidant and resistant (or ambivalent) children to be more at risk for the development of later adjustment problems as compared to those classified as securely attached (Cassidy \& Berlin, 1994; Rubin, Bukowski, \& Parker, 1998). A third insecure attachment category-disorganized (or disoriented) attachment - is also associated with emotional and social dysfunction during childhood (Main, 1994). Children with a disorganized (or disoriented) attachment style exhibit a confused and unstable relatedness pattern, which usually includes behaviors characteristic of both avoidant and resistant (or ambivalent) categories randomly (Lyons-Ruth,
Connel, Gruneubaum, \& Botein, 1990; Main, 1994).

Finnegan, Hodges, and Perry's (1996) research on the assessment of relatedness stances in middle childhood relies on attachment theory's conceptualization of resistant-preoccupied and avoidant-dismissing attachments at younger and older ages (Finnegan et al., 1996). Finnegan and her colleagues have explored the hypothesis that when excessive dependency needs that threaten autonomic functioning or excessive autonomy needs that inhibit emotional closeness characterize children's relatedness to significant others, optimal functioning may be impaired (Hodges, Finnegan, \& Perry, 1999). They have suggested that these skewed relatedness stances are directly associated with maladjustment during middle childhood. In order to test this hypothesis, they developed self-report scales that assess the degree to which school-age children relate to their mothers in an overly preoccupied or avoidant pattern. Children who are high on the Preoccupied Scale report experiencing a strong need for the mother's presence in novel or stressful situations, trouble separating from the mother, prolonged upset following reunion, and trouble exploring new challenges due to excessive need for the mother. Children who are high on the Avoidant Scale report denial of distress and affection toward the mother, failure to seek the mother when upset, and refusal to use the mother as a task-relevant resource. Children with a disorganized attachment style may exhibit an extreme skewness toward both an avoidant and a preoccupied stance in the relationship with their mother, but Finnegan and associates' method does not directly assess a disorganized stance and is therefore not included in the present study.

Finnegan and colleagues (1996) and Hodges and colleagues (1999) have shown significant associations between skewed relatedness stances and behavioral problems. These authors found that skewed preoccupied and avoidant stances predicted an increase in internalizing and externalizing problems over a 1-year period beyond the preliminary levels reported for these problems. These studies, however, did not explore the associations among these variables and children's representations of the mother. 
The importance of exploring concomitantly children's relatedness stance and their representations of the mother stems from the differences as well as complementarities between these two variables. While we define children's representations of the mother, as measured by the ORI, as internal templates capturing enduring affective contents associated with the maternal object, the definition of skewed relatedness stances does not refer to children's representations of the attachment figure (e.g., the availability, responsiveness, or dispositions of the mother) but rather to selfperceived typical thoughts and behaviors toward the mother (Finnegan et al., 1996). Moreover, while children's representations of the mother tap more unconscious affective contents, relatedness stances tend to capture consciously accessible self-perceptions of behavior toward the mother. Finally, according to Finnegan and colleagues (1996), the relatedness stance scales do not tap the manner in which the child represents specific attributes of the caregiver (i.e., benevolence, sensitivity, or motivations of the mother) but refer to characteristic stances toward the mother in potentially stressful everyday situations.

In the present study, we were interested precisely in exploring the associations between children's more stable, consolidated, partly unconscious representations of the maternal figure and their perceived interaction tendencies in present-day situations with her. Empirical research to date has provided some evidence linking children's internal representations of the mother and adjustment outcomes (Priel et al., 1995; Priel et al., 2000; Westen et al., 1991), as well as their relatedness stance and problem behavior (Finnegan et al., 1996; Hodges et al., 1999). Nonetheless, previous researchers have not explored the associations between aspects of children's maternal representations and their relatedness stances, nor have they tested the relationship between these variables and problem behavior in middle childhood. We suggest that an uncaring and threatening maternal representation is associated with an overly dependent or autonomic relatedness stance to mother, which is in turn associated with problematic and maladaptive behavior.

\section{Children's self-representations}

Parallel to the centrality of children's representations of relationships, social-cognitive theory and research have stressed the role of children's self-representation as a pivotal factor affecting their adjustment during the middle childhood (Baumeister, 1990; Damon \& Hart, 1988; King, Naylor, Segal, Evans, \& Shain, 1993). Additionally, both attachment and psychoanalytic theorists have conceptualized children's internal representation of significant caretakers to influence their selfrepresentations significantly (Harter, 1986). In general, these perspectives assume that internal representations or working models of a caring and reliable parent facilitate the construction of positive self-representations, while unpredictable or rejecting parental representations lead to the construction of negative representations of the self (Blatt, 2004; Blatt et al., 1997; Main et al., 1985; Waniel et al., 2006).

Research on school-age children samples has shown significant associations between the affective content of the self-representation (i.e., self-esteem or self-worth) and different adjustment outcomes (Ryan, Stiller, \& Lynch, 1994). Moreover, children seem to be processing their relationship patterns with their parents and their self-individuation and worth in an interdependent manner (e.g., Hodges et al., 1999). This processing includes both a basic attachment to and an increasing differentiation from parental figures. Researchers on the social-cognitive tradition point out that attachment to parents and the self-definition process play a fundamental role during this stage (Ryan et al., 1994; Toth \& Cicchetti, 1996).

Research on school-age children has mainly addressed the perception of self and relatedness separately. Findings have shown positive selfrepresentations to associate with better behavioral adjustment and fewer behavioral problems (Baumeister, 1990; Damon \& Hart, 1988; King et al., 1993; Segal \& Blatt, 1993) and children's representations of relationships to correlate with adjustment in middle childhood (Allen, Hauser, Eickholt, Bell, \& O'Connor, 1994; Baldwin, 1992; Frank, Pirsch, \& Wright, 
1990). In addition, Ryan and colleagues' (1994) study centered upon the relations between representations of significant others and a specific aspect of the self - self-esteem. In a previous study we conducted on a sample of schoolage children (Waniel et al., 2006), we found significant associations between subjects' maternal and self-representations and confirmed the hypothesis that children's self-worth functioned as a mediator of the association between the content of their maternal representation and overall levels of problem behavior. In the present study, we intended to test the assumed parallel role of children's selfrepresentation and their relatedness stance to mother as plausible factors associated with levels of maladaptive behavior.

\section{The present study}

The above-cited theory and research seem to indicate that children's inner representations of the mother are related to adjustment through their impact on processes of self-formation, on the one hand, and on characteristic behaviors and attitudes in significant relationships, on the other hand. The present study aimed to further the investigation of the relationships between basic aspects of perception of both relatedness to mother and self and their separate and conjoint contributions to children's psychological adjustment and competence.

Using a longitudinal design (two waves of measurement) allowed for mediators (relatedness stance and self-worth) and outcome variables (child problem behavior) to be separated by measurement times. A 10-month period gap (the beginning and end of the same academic year) allowed for such a separation without surpassing the present study's developmental stage focus. Finally, gathering child problem behavior data (outcome) through teachers' reports further ensured that predictors and outcome variables do not share common source variance.

We investigated the following hypotheses:

H1: Qualitative aspects of children's representations of the mother measured at Time 1 are significantly associated with levels of problem behavior measured at
Time 2. If this hypothesis is confirmed, this finding will serve as a replication of the previously demonstrated association between children's maternal representation and their subsequent behavior.

H2: Skewed relatedness stances toward the mother mediate the association between children's representations of the mother and problem behavior.

H3: Self-representations and skewed relatedness stances toward the mother are independent and parallel mediators of the association between children's representations of the mother and their problem behavior.

\section{Method}

\section{Participants and procedure}

Participants were 203 children aged 9-11 years at the first measurement wave $(M=$ $10.10, S D=0.55)$. We recruited children from two elementary schools in an Israeli urban middle-class community after obtaining approval of the Israeli Ministry of Education Ethics Committee. It is important to note here that we approached all parents of the children potentially eligible for participating in the study through a letter informing about the study along with a written informed consent form in accordance with the Ethics Committee guideline. Our final sample included children whose parents signed the informed consent form. ${ }^{1}$ Eighty-nine percent of the parents and children approached consented to take part in the study. Eight percent of the study's participants did not complete either one or two

1. This sampling method may be considered as a convenience sample. Although we selected these particular schools also according to socioeconomic indices defined by the Israeli Ministry of Education to be representative of Israeli urban middle-class community schools, we refer to limitations related to generalizability of such a nonrandomly selected sampling in the Discussion section. 
assessments of the Relatedness Stance Questionnaire (RSQ) due to absence at the time of administration and were therefore not included in the study's sample.

The study proceeded in two consecutive measurement waves. The first assessment wave included the administration of the maternal representation interview using the Children's Object Representation Inventory (CORI; Waniel et al., 2006), the self-representation interview using the Manual for the Coding of Children's Self-Descriptions (CCSD; Waniel et al., 2006), and the RSQ (Finnegan et al., 1996) to the children. For the administration of the CORI and the CCSD, we interviewed children individually in their school setting in a quiet and private classroom the school faculty provided. We administered the RSQ to the children in groups of 10-12 participants in a separate and quiet classroom. Items on the RSQ were tape-recorded and played to the children as they followed along and marked their responses.

The second assessment wave, carried out 10 months later, included the administration of the Achenbach's Teacher Report Form (TRF; Achenbach, 1991; Achenbach \& Rescorla, 2001) to the children's homeroom teachers. The research staff gave the seven homeroom teachers participating in the study detailed instructions for the completion of the checklist, specifically concerning the scaling of problems' gravity, with a research assistant present for questioning during completion.

We recruited four graduate students from the Clinical Psychology Program and trained them as interviewers for this project. The homeroom teacher in each class presented the interviewer to the children, after which the interviewer gave an explanation and asked the children to take part in a study about "how children perceive themselves and their mothers." We conducted the interviews in Hebrew. These semistructured interviews were designed to obtain open-ended, spontaneous descriptions of self and mother. We interviewed the children separately about their mother and themselves in random order. After creating a comfortable atmosphere and rapport, we asked participants to tell about their mother or self with no further specification.
After each spontaneous description, the interviewer encouraged the children in a nondirective way to expand their response (e.g., "Is there something else you would like to tell about Mom [or yourself]?"). The spontaneous answers to these questions were rated as the narrative. The interviewer further probed the participants if there were aspects of the description that remained unclear or ambiguous. We did not code the probes themselves but used them only to help in coding the spontaneous descriptions.

\section{Measures}

Children's representations of the mother. We evaluated children's representations of the mother using the CORI (Waniel et al., 2006), an adaptation of the ORI, which Blatt and colleagues (1992) devised for the evaluation of adult and adolescent representations of significant others. The coding procedure of the CORI included seven qualitative or content categories and a structural scale (for a detailed description, see the appendix in Waniel et al., 2006). We rated the content categories on a 7-point scale. The seven content scales converge into a single latent construct defined as Care. The Care construct consists of the following categories: affectionate, cold-warm, constructive involvement, nurturant, weak-strong, judgmental, and punitive. The first five categories address aspects related to the degree of benevolence attributed to the maternal figure, ranging from descriptions of an uninvolved and uncaring maternal figure to a warm and benign one. The remaining two categories, judgmental and punitive, address the degree to which participants experience the maternal figure as threatening and disapproving, ranging from descriptions of a nonpunitive and acceptant maternal figure to a punishing and highly critical one (the latter two are inversely loaded on the Care construct).

We evaluated the main structural characteristic of the maternal representation through the Conceptual Level Scale, ranging from sensorimotor and concrete levels of representation to abstract and complex ones. In the present study, we were interested in the qualitative construct of the Maternal Representation. Specifically, we were interested in exploring 
whether children's Maternal Representation Care levels would be related to their perception of self and relationships. Accordingly, we rated and used the qualitative scales of children's representations of the mother comprising the Care construct. Confirmatory factor analyses have shown the replicability and validity of the Maternal Representation factor structure described above (Waniel et al., 2006). ${ }^{2}$

Four undergraduate psychology students independently rated the maternal descriptions. Raters were blind to the subjects' selfdescriptions. These raters participated in both theoretical and practical training by a psychologist, an expert in the CORI assessment. These raters had previously established acceptable levels of interrater reliability in scoring CORI scales on training protocols. The interrater intraclass correlation reliability coefficients (Shrout \& Fleiss, 1979) obtained for each of

2. Although the structural aspect of the CORI (i.e., Conceptual Level) was not part of the present study, we give some examples of this scale below: At the sensorimotor-preoperational level, participants experience the parent primarily in terms of need gratification. A typical phrase of a description at this level is "She buys me presents, makes the cakes I love and sometimes takes me to the swimming pool ..." At the perceptual-concrete level, participants describe the parent as separate from specific experiences of gratification and recognize him or her as a generalized entity in concrete, literal, and demographic terms. For instance, "My Mum is very pretty, she has green eyes and always dresses in fancy clothing ..." The qualities and attributes of representations at the external-iconic level are based on specific manifest properties, such as behaviors and interests of the parent or additional caregiver. For instance, "My Mum does a lot of sport, she runs, swims, walks a few times a week ..." At the internaliconic level, representations reflect mainly an appreciation of more abstract and internal properties, such as feelings and thoughts. For example, "My mother is very warm and nice. She likes to make the people she is with feel good. She simply likes people and likes to give ..." At the conceptual-representational level, participants represent the parent as fully integrated and with enduring characteristics and a sense of history. For instance, "My mother is a very strict sort of person. When she does something, she wants it to be perfect. She is sometimes kind of irritable, but she can also be very patient, for instance when I want to tell her something or when I'm sad ... And not only with me, it can be with others." We coded the conceptual level of the representation on a 9-point scale, including the five levels mentioned above (scores 1, 3, 5, 7, and 9, respectively) and four intermediate levels (scores 2, 4, 6, and 8 , respectively) that we used for narratives that fall in between these levels. the seven categories in the present study ranged from .88 to .94 . When scores were not identical, we used the mean score.

Children's self-representations. We evaluated children's self-representation using the CCSD (Waniel et al., 2006), an adaptation of Blatt and colleagues' coding procedure of open-ended self-descriptions in adult populations (Blatt, Bers, \& Schaffer, 1993). The following four categories, devised to capture central qualitative aspects of the representation of self (Priel et al., 2003), converge into a latent construct defined as Self-Worth: felt security, cold-warm, competence, and agency. These categories address aspects related to the extent to which the self is experienced as worthy and loved, ranging from negative descriptions involving critical and devaluating self-feelings to positive descriptions involving warm and competent feelings toward the self. In addition, two categories, reflectivity and substantiality, devised to capture central structural aspects of the representation of self, converge into a latent construct defined as Reflectivity. These categories address the extent to which the self-description is diverse and reflective regardless of the description's content. Confirmatory factor analyses have shown the replicability and validity of the Self-Representation structure described above (Waniel et al., 2006).

In accordance with the present study's theoretical emphasis, we were interested in the qualitative aspect of children's self-representations and accordingly rated and used the four qualitative scales constituting the Self-Worth construct. Four independent raters, blind to the subjects' maternal descriptions, rated all selfdescriptions. The interrater intraclass correlation reliability coefficients (Shrout \& Fleiss, 1979) for each of the four self-description scales ranged from .82 to .96 . When scores were not identical, we used the mean score.

Problem behavior. We assessed children's problem behavior by means of teachers' reports of behavioral and emotional problems using the Externalizing and Internalizing problems factors of the TRF (Achenbach, 1991; Achenbach \& Rescorla, 2001), a standardized 
teacher report questionnaire designed to assess behavioral problems in children aged between 5 and 18 years. Zilber, Auerbach, and Lerner (1994) translated the 113-item TRF checklist into Hebrew and adapted it to Israeli child populations. The Externalizing problems factor of the TRF includes the presence of delinquent and aggressive behavior. The Internalizing problems factor of the TRF relates to withdrawn, anxious-depressed, and somatic complaints. The TRF has high concurrent validity $(>.80)$ and associates significantly with the Diagnostic and Statistical Manual of Mental Disorders criteria (Achenbach \& Rescorla, 2001). In the present study, we obtained internal consistency coefficients' Cronbach's alpha scores of .70 and .70 for the Externalizing and Internalizing problems factors, respectively.

RSQ. This 30-item questionnaire, which Finnegan and colleagues (1996) developed, measures preoccupied and avoidant relationship stances toward the mother (15 items per scale). Each item on the scale measuring preoccupied stance describes two reactions to a stressor - a preoccupied response and a nonpreoccupied response - and children choose the response they would be more likely to make. The preoccupied response options describe children who are experiencing a strong need for the mother in stressful and novel situations, trouble separating from the mother, excessive concern over the mother's whereabouts, continued upset following reunion, and trouble exploring or meeting challenges owing to excessive need for the mother. Nonpreoccupied options describe children behaving in a way presumably reflective of healthier adaptation. Following is a sample item from the Preoccupied Scale (the preoccupied option is the second option):

You and your mother are at a busy shopping mall in Beer-Sheba, and suddenly you can't find your mother. You are upset, but a little later you find each other. Some kids would soon get over being upset, but other kids would stay worried for a long time that they might get separated again. Which is more like you?
For each item, children first indicate which of the two possible reactions to a stressor they would be more likely to make and then indicate whether this choice is really true or sort of true for them. We scored response to items on the Preoccupied Scale by assigning values of 0,1 , and 2 to response options indicating that the self was, respectively, (a) really like children who would make the nonpreoccupied response, (b) sort of like children who make the nonpreoccupied response, (c) sort of like children who would make the preoccupied response, and (d) really like children who would make the preoccupied response. We assigned a value of 0 to both the nonpreoccupied options because neither indicated any degree of preoccupation. Thus, total scores on the Preoccupied Scale could range from 0 to 30 .

We wrote the items on the scale measuring avoidant stance analogously to those on the Preoccupied Scale, with children choosing between avoidant and nonavoidant response options. Avoidant options depict children who deny distress and affection concerning the mother, fail to seek the mother when upset, avoid the mother during exploration and reunion, and refuse to use the mother as a task-relevant resource. Following is a sample item:

Your mother comes home after being away for a week or two. Some kids would stop what they are doing to greet her, but other kids would not stop what they are doing to greet her. Which is more like you?

We scored the items on the Avoidant Scale analogously to those on the Preoccupied Scale (i.e., with a value of 0 assigned to both nonavoidant options and values of 1 and 2 assigned, respectively, to lesser and greater endorsement of avoidant options), so scores could again range from 0 to 30 .

For the present study, we translated the RSQ and adapted it to Hebrew. The translation process included three phases. First, a graduate student, thoroughly proficient in both English and Hebrew languages, translated the questionnaire items from English to Hebrew. The translation included also slight adaptations to 
Israeli children's daily life habits as compared to those of American children described in some of the items of the original questionnaire (e.g., while American children tend to spend time in summer camp during vacation or visiting a mall on an everyday basis, Israeli children tend to spend time away from home visiting family members or family friends or visiting open shopping areas on an everyday basis). Then, another proficient English- and Hebrew-speaking graduate student, unfamiliar with the original English version, translated the questionnaire from Hebrew back to English. Finally, we compared the two English versions to track items, which may have been distorted by the translation process, and refined these items in the final Hebrew version. We then administered the final Hebrew version to six Israeli children, aged 9-11 years, unrelated to the study sample in order to receive feedback on the clarity of the Hebrew items. We further refined the items the children specified as unclear by changing a few words without changing the content of the item. Reliability (Cronbach's alpha) for the present Israeli sample was .80 and .76 for the Preoccupied Scale on the first and second assessment waves, respectively, and .71 and .76 for the Avoidant Scale, respectively.

\section{Analytic strategy}

Our analyses focused on tests of mediational effects. Specifically, does Relatedness Stance (a latent construct defined using the Preoccupied and Avoidant Scales' scores as its indicators) or Self-Worth mediate the effect of Maternal Care on problematic behavior (Externalizing and Internalizing factor scores)? (The Maternal Care and Self-Worth latent constructs were specified by their corresponding indicators as described in the Method section.) We explored this question using a structural equation modeling (SEM; Hoyle, 1995) strategy that allows for the simultaneous evaluation of both the direct and the mediating effects while assessing measurement errors in the dependent and independent variables. We performed all SEM analyses with the Amos software (Version 4.01; Arbuckle, 1999) using the maximum likelihood method.
We conducted the analysis in three stages. First, to explore the overall fit of the full measurement model, we performed a confirmatory factor analysis (Anderson \& Gerbing, 1988) that revealed the accuracy of the underlying structure of the latent variable used in a measurement model. Table 1 presents the intercorrelations between the study variables. These data depict the first-order correlations among the separate observed indicator variables that are not available through the assessment of the relations among the latent construct and observed measures examined in the measurement and in the structural models presented in Table 2. Only after demonstrating the acceptability of the underlying constructs, we proceeded with the investigation of structural models.

Second, we employed SEM to examine the direct effect of Maternal Care (predictor) separately on Internalizing and Externalizing factor scores. Finally, in the third stage, we employed SEM to examine the mediating model proposed, where we specified Relatedness Stance as a mediator of the Maternal Care effect separately on Internalizing and Externalizing scores (Figures 1 and 2). We specified these mediation paths beyond the mediation of the Maternal Care construct's direct effect on Internalizing and Externalizing scores by Self-Worth.

We conducted the analyses by means of the Amos 4.01 program (Arbuckle, 1999). We used the chi-square statistic as a fit index to evaluate how the proposed model (i.e., the model being evaluated) fits the data as compared to the saturated model (i.e., the baseline model that represents perfect model fit). A nonsignificant chi-square is traditionally used as a criterion for not rejecting an SEM model; a nonsignificant chi-square indicates that the discrepancy of the matrix of the parameters estimated based on the model being evaluated is not different from the one based on the empirical data. Nonetheless, this is a very strict, sensitive criterion that is influenced by the number of variables and participants (Landry, Smith, Swank, \& Miller-Loncar, 2000). We therefore used additional fit indices: the $\chi^{2} / d f$ ratio, the root mean square error of approximation (RMSEA), the comparative fit index (CFI), and the nonnormed fit 


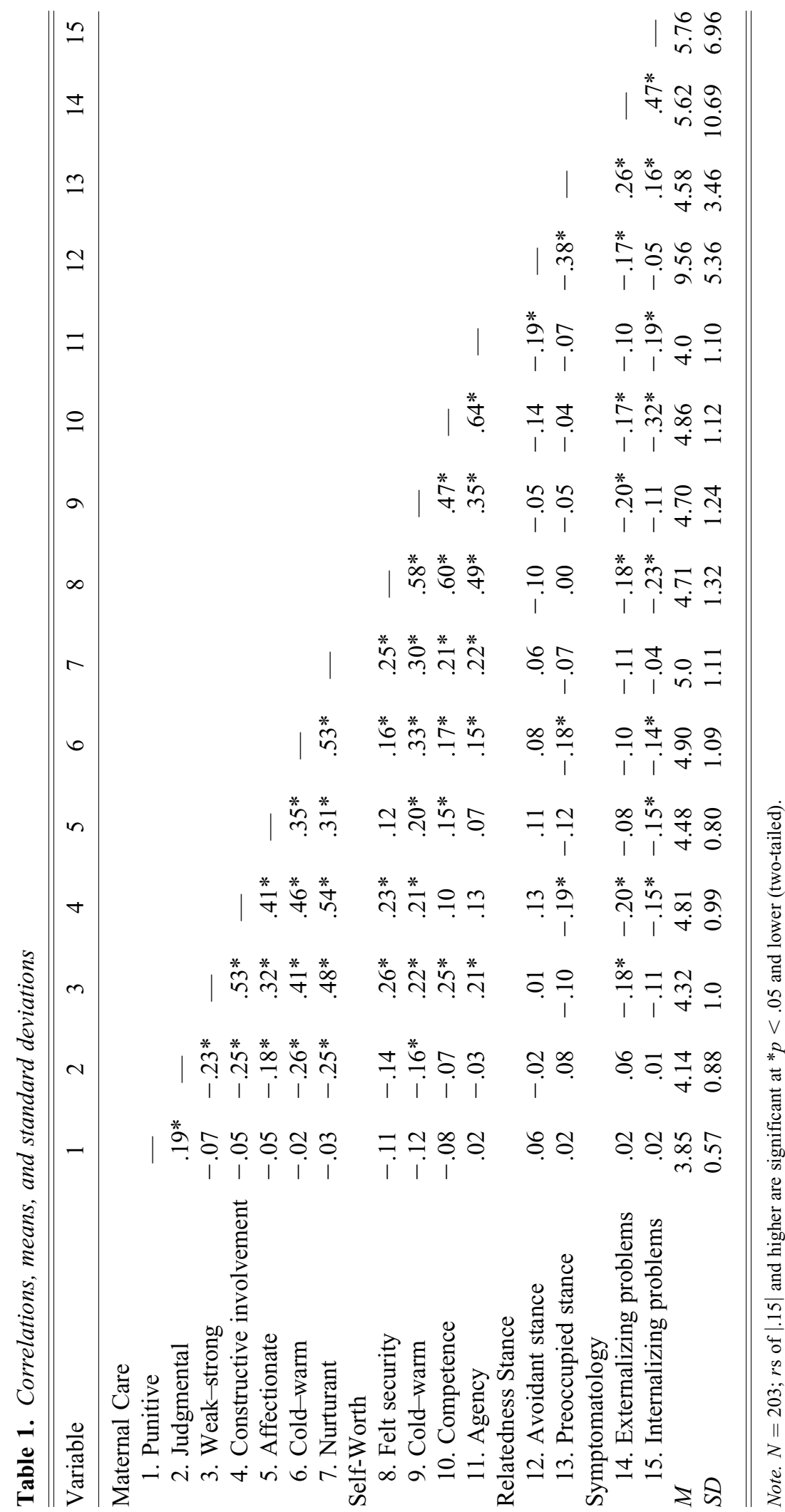


Table 2. Results for measurement model

\begin{tabular}{|c|c|c|c|c|c|}
\hline \multirow[b]{2}{*}{ Variable } & \multicolumn{5}{|c|}{ (a) Factors loading coefficients and $R^{2}$} \\
\hline & Maternal Care & Self-Worth & Relatedness Stance & $R^{2}$ & \\
\hline 1. Punitive & .35 & & & $.12 *$ & \\
\hline 2. Judgmental & -.35 & & & $.12 *$ & \\
\hline 3. Weak-strong & .68 & & & $.46^{* * *}$ & \\
\hline 4. Constructive involvement & .77 & & & $.59 * * *$ & \\
\hline 5. Affectionate & .51 & & & $.26^{* *}$ & \\
\hline 6. Cold-warm & .63 & & & $.39 * * *$ & \\
\hline 7. Nurturant & .69 & & & $.48^{* * *}$ & \\
\hline 8. Felt security & & .69 & & $.48 * * *$ & \\
\hline 9. Cold-warm & & .54 & & $.29 * * *$ & \\
\hline 10. Competence & & .87 & & $.76^{* * *}$ & \\
\hline 11. Agency & & .72 & & $.52 * * *$ & \\
\hline 12. Avoidant stance & & & -.59 & $.35^{* *}$ & \\
\hline \multirow[t]{3}{*}{ 13. Preoccupied stance } & & & .64 & $.41 * * *$ & \\
\hline & \multicolumn{5}{|c|}{ (b) Correlations among latent variables } \\
\hline & 1 & 2 & 3 & 4 & 5 \\
\hline 1. Maternal Care & - & & & & \\
\hline 2. Self-Worth & $.34 * * *$ & - & & & \\
\hline 3. Skewed Relatedness & $-.25 * *$ & .08 & - & & \\
\hline 4. Externalizing problems & $-.22 * *$ & $-.20^{*}$ & $.36^{* * *}$ & - & \\
\hline 5. Internalizing problems & $-.17^{*}$ & $-.33 * *$ & $.18^{*}$ & $.47 * * *$ & $\longrightarrow$ \\
\hline
\end{tabular}

${ }^{*} p<.05 .{ }^{* *} p<.01 .{ }^{* * *} p<.001$

index (NNFI; Bentler \& Bonett, 1980). We chose to accept a model in which the $\chi^{2} / d f$ ratio is $\leq 2$ or in which the CFI and NNFI are greater than .90 . These moderately stringent acceptance criteria will clearly lead to the rejection of inadequate or poorly specified models while leading to the acceptance of models that meet real-world criteria for reasonable fit and representation of the data (Kelloway, 1998).

\section{Results}

\section{Measurement models}

Before testing a structural model for mediation, we defined a measurement model that included Time 1 assessments of the Maternal Care, the Self-Worth, and the Relatedness
Stance constructs and the Externalizing and Internalizing problems manifest variables ${ }^{3}$ (Figures 1 and 2). We defined the latent construct of Relatedness Stance using subjects' Avoidant Stance and Preoccupied Stance scores as its indicators. We specified the constructs of Maternal Care and Self-Worth according to the factor structure found to be reliable for children at this age-group (Waniel et al., 2006). Table 1 presents the means, standard deviations, and intercorrelations between the models' manifest variables. The present model allowed us to test for the plausibility of a latent construct of Relatedness Stance

3. Measurement model is the mapping of measures onto theoretical constructs. After verifying the acceptability of the underling constructs, the structural model includes the causal and correlational links between theoretical variables. 


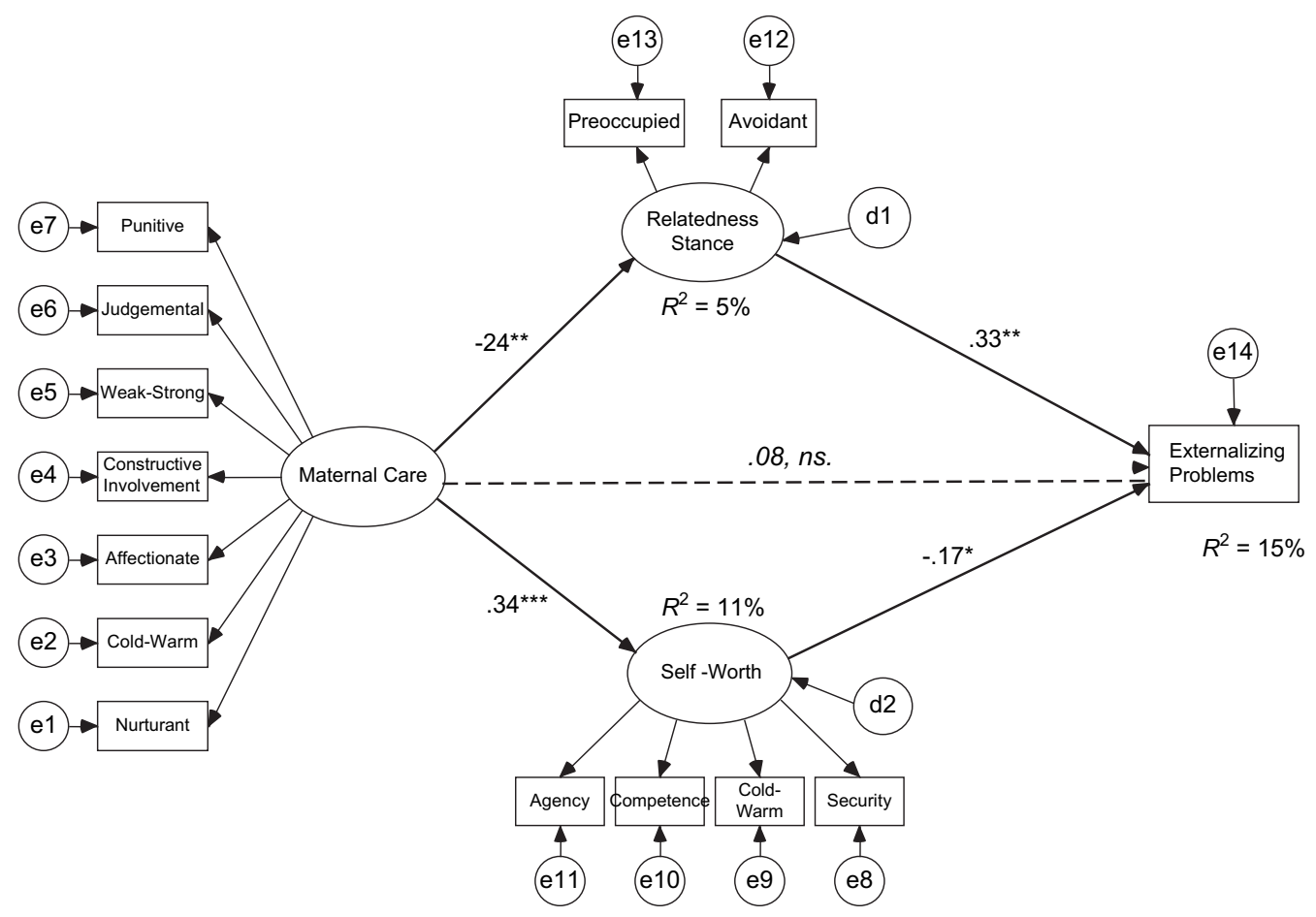

Figure 1. The direct and indirect mediational model on Externalizing problems.

Note. Rectangles indicate measured variables, and large circles represent latent constructs. Small circles reflect (e) residuals or (d) disturbances. Unidirectional arrows depict hypothesized directional, or "causal," link. Standardized maximum likelihood parameters are used. The indirect effect from Maternal Care to Externalizing through Relatedness Stance contributed a significant $13 \%$ to the variance in Symptomatology, and the indirect effect through Self-Worth contributed only an additional significant $2 \%$.

$* * p<.01 . * * * p<.001$.

and for its intercorrelations with the representations' and Externalizing and Internalizing problems. The model also allowed us to confirm the fit of the maternal and selfrepresentations' content constructs, as well as the intercorrelations among the defined latent constructs and Externalizing and Internalizing problems, in the present sample. The specified measurement model had a plausible fit to the observed data, $\chi^{2}(80, N=203)=$ 99.04, $\chi^{2} / d f=1.2, p>.07, \mathrm{CFI}=.94, \mathrm{NNFI}$ $=.97, \mathrm{RMSEA}=.03, \mathrm{CI}=0.00$ to 0.05 . All the factor indicators and path loadings were substantial and statistically significant in the expected direction (Table 2). Specifically, the Relatedness Stance construct was found to explain $35 \%$ and $41 \%$ of the avoidant and preoccupied indicators, respectively, with re- spective path coefficients of -.59 and .64 . Note that the avoidant and preoccupied indicators are inversely loaded on the Relatedness Stance construct. It is also important to note that although the predictor (Maternal Care) and the mediators (Relatedness Stance and Self-Worth) were not separated by measurement times, the intercorrelation between them is moderate $(-.25, t=-2.01, p<.04$ for Relatedness Stance; .34, $t=3.31, p<.001$ for Self-Worth), showing them to be different, though associated, constructs.

\section{Mediational models}

In order to explore the hypothesis that Relatedness Stance and Self-Worth mediate the association between Maternal Care and 


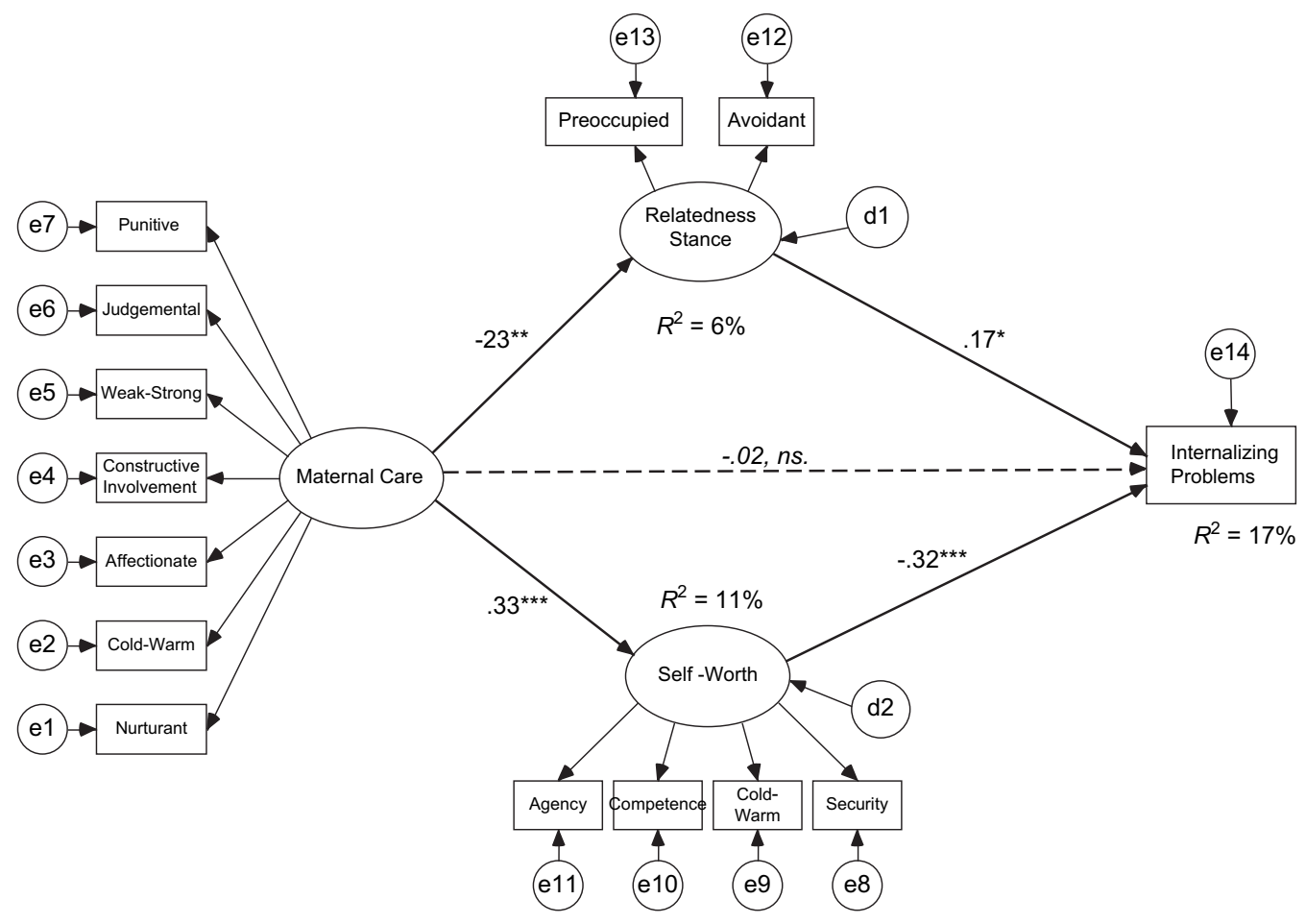

Figure 2. The direct and indirect mediational model on Internalizing problems.

Note. Rectangles indicate measured variables, and large circles represent latent constructs. Small circles reflect (e) residuals or (d) disturbances. Unidirectional arrows depict hypothesized directional, or "causal," link. Standardized maximum likelihood parameters are used. The indirect effect from Maternal Care to Internalizing through Self-Worth contributed a significant $10 \%$ to the variance in Symptomatology, and the indirect effect through Relatedness Stance contributed a significant additional $7 \%$.

${ }^{*} p<.05 .{ }^{* *} p<.01 .{ }^{* * *} p<.001$.

Externalizing and Internalizing problems, we used the following analytic strategy.

We initially followed Baron and Kenny's (1986) criteria for mediation, according to which (a) there must be a significant association between the predictor and the criterion variables and (b) in an equation including both the mediator and the criterion variables, there must be a significant association between the predictor and the mediator and the mediator must be a significant predictor of the criterion variable. If the significant direct relationship between the predictor and the criterion variables in the equation including both the mediator and the predictor variable declines, the obtained pattern is consistent with the mediation hypothesis. If the direct association approaches zero, the mediator fully (although not necessarily exclusively) accounts for the relation between predictor and criterion (Baron \& Kenny, 1986). Thus, first we analyzed the direct effects of Maternal Care on Externalizing and Internalizing scores. Then, we specified the direct and indirect effect models of Maternal Care on the Externalizing and Internalizing scores (Figures 1 and 2).

Nonetheless, although Baron and Kenny's (1986) recommendations are influential and extensively cited, some recent criticisms have been raised (MacKinnon, Lockwood, Hoffman, West, \& Sheets, 2002) especially about their use of Sobel's (1982) large-sample test to test the significance of the indirect effect. Therefore, we evaluated our proposed 
mediational model by studying the sampling variability of estimates of the indirect effect using the bootstrap framework Shrout and Bolger (2002) and Mallinckrodt, Abraham, Wei, and Russell (2006) recently implemented for mediation in SEM.

Direct effect models. We first confirmed the existence of a significant direct relation between Maternal Care and Externalizing problems. This model fits the observed data well, $\chi^{2}(19, N=203)=13.31, \chi^{2} / d f=0.7$, $p>.82, \mathrm{CFI}=1.0, \mathrm{NNFI}=.98, \mathrm{RMSEA}=$ .00 , with Maternal Care found to be significantly associated with lower levels of Externalizing problems $(\beta=-.22, t=-2.73, p<$ $.01 ; S E=1.19, \mathrm{CI}=-5.82$ to $-1.08, p<$ $.003)$, explaining $5 \%$ of the Externalizing variance. Then, we confirmed the existence of a significant direct relation between Maternal Care and Internalizing problems. This model also fits the observed data well, $\chi^{2}(19, N=$ 203) $=16.38, \chi^{2} / d f=0.86, p>.63, \mathrm{CFI}=$ $1.00, \mathrm{NNFI}=.95$, RMSEA $=.00$, with Maternal Care significantly associated with lower levels of Internalizing problems $(\beta=-.17$, $t=-2.09, p<.04 ; S E=0.73, \mathrm{CI}=-3.30$ to $-0.16, p<.02$ ), explaining $3 \%$ of the Internalizing variance.

Mediational effect models. Finally, we tested whether the indirect relation between Maternal Care (predictor) and Externalizing or Internalizing problems (outcomes) through Relatedness Stance (mediator) significantly reduced the Maternal Care construct's direct relation to problematic behavior. We therefore specified a model (Figures 1 and 2) in which we defined the Maternal Care construct to have both a direct path to Externalizing or Internalizing problems and an indirect path: one through Relatedness Stance and one through Self-Worth, thus testing the Relatedness Stance construct as an additional mediator beyond the demonstrated mediating role of the Self-Worth construct (Waniel et al., 2006).

As noted earlier, the direct paths from Maternal Care to Externalizing or Internalizing problems were significant. In Figures 1 and 2, however, these paths approached zero $(\beta=-.08, S E=1.28, \mathrm{CI}=-3.47$ to 1.41 , $p>.44$ and $\beta=-.02, S E=0.83, \mathrm{CI}=-1.93$ to $1.34, p>.88$, respectively). As can be seen in Figures 1 and 2, Maternal Care was significantly associated with Self-Worth which in turn was associated with Externalizing $(\beta=$ $-.17, S E=1.27, \mathrm{CI}=-4.93$ to $0.07, p<$ $.03)$ and Internalizing $(\beta=-.32, S E=0.69$, $\mathrm{CI}=-3.83$ to $-1.06, p<.003)$ problems; Maternal Care was also significantly associated with Skewed Relatedness, which in turn was associated with Externalizing $(\beta=.33$, $S E=0.51, \mathrm{CI}=0.50$ to $2.38, p<.002)$ and Internalizing $(\beta=.17, S E=0.30, \mathrm{CI}=0.001$ to $1.13, p<.04)$ problems.

Overall, our analyses indicated that while Self-Worth is not associated with Relatedness Stance, the associations between Maternal Care and Externalizing or Internalizing problems are significantly mediated by the SelfWorth $(S E=0.55, \mathrm{CI}=-2.28$ to $0.02, p<$ .05 for Externalizing and $S E=0.35, \mathrm{CI}=$ -1.81 to $-0.43, p<.002$ for Internalizing) and the Relatedness Stance $(S E=0.57, \mathrm{CI}=$ -2.72 to $-0.24, p<.01$ for Externalizing and $S E=0.27, \mathrm{CI}=-1.16$ to $0.00, p<.04$ for Internalizing) constructs. Both the Self-Worth and the Relatedness Stance constructs mediated the effects of Maternal Care on both Internalizing and Externalizing problems. Findings were significantly stronger for Externalizing problems. The Relatedness Stance effect was stronger on Externalizing problems, while Self-Worth effect was stronger on Internalizing problems.

\section{Discussion}

In the context of the study of processes linking internal representations and problem behavior during middle childhood, we were interested in exploring whether children's representations of the mother were associated with maladaptive stances of interpersonal relatedness or negative self-representations and whether these may then contribute to maladjustment.

The results of the present study provide evidence for the mediational role of the relatedness stance in the association between children's representations of the mother and their adjustment. More specifically, our results show that a representation of the mother as low 
in care and nurturance may contribute to a skewed pattern of relatedness to her, which may in turn be associated with problem behavior. The association between the content of children's maternal representation and their relatedness stance is akin to studies reporting significant relationships between the content and the structure of adult subjects' representations of the mother and their attachment styles (Calabrese, Farber, \& Westen, 2005; Levy et al., 1998; Priel \& Besser, 2001). In the present study, we found a moderate negative intercorrelation between the Preoccupied and the Avoidant Stances, possibly reflecting their related tendencies or patterns of interaction. Our extended mediation model reinforces the assumption that representations of the mother are associated with the more cognitively accessible perceptions of mother-child interaction. These perceptions, or stances, are in turn associated with the child's actual functioning and adaptive capabilities. Findings of the present study regarding the role of children's skewed relatedness stances and their problem behavior are in line with the existing empirical evidence showing high avoidance and ambivalence (or resistance) to be vulnerability factors (e.g., Goldberg, Muir, \& Kerr, 1995; Schneider, Atkinson, \& Tardif, 2001).

Our findings may reflect attachment and object relations theories' premise that the child's maternal representation, or internal model, influences expectations as well as general patterns of behavior that characterize mother-child interpersonal relationships across the life span (Diamond \& Blatt, 1994; Slade \& Aber, 1992). It is possible to understand the mediating role of Relatedness Stance as a mechanism through which the child translates the internal working model or representation into characteristic interpersonal perceptions and reactions. From a similar perspective, our findings support the assumption that underlying insecure or nonbenevolent representations of their caregivers influence children's skewed interpersonal stance. Although we interpret our results as supportive of these hypotheses, our design did not preclude transactional influences between internal representations and interpersonal stances, so that, for example, children's relatedness stance with their caregiver may influence their parental representations. This possibility may constitute an important step in understanding the complexity of influences on children's psychosocial and behavioral outcomes, of which parent-child relationships are only one element (Goldberg et al., 1995).

It is important to note here that a skewed avoidant or dependent stance is a continuous and not categorical variable, much like current conceptualizations of attachment and personality styles (Levy et al., 1998; Pietromonaco \& Feldman-Barett, 2000). This is most important in the interpretation of our findings, showing that higher levels of avoidance were positively associated with maladjustment independent of children's tendency toward a preoccupied stance. Such a result indicates that an overemphasis on autonomy needs may be a vulnerability factor also at this developmental stage. Although we found the Avoidant and Dependent Scales to be inversely loaded on the Relatedness Stance construct, it does not mean that they are orthogonal or that children are either avoidant or dependent types in their relatedness stance to mother and are accordingly well adjusted or maladjusted.

The general theoretical model defining selfand parental representations as basic templates guiding behavior and cognition is relevant to the explanation of adjustment in middle childhood. Nonetheless, other temperamental and situational factors interact with internal schemas of self and parent in order to create the complex matrix of school-age children's behavior. Nevertheless, the present research offers some evidence linking children's complex internal representations of the mother with their problem behavior. Our findings seem to show that children's inner representations of the mother are related to adjustment through their associations with processes of formation of the self, on the one hand, and with characteristic perceptions and attitudes in significant relationships, specifically with mother, on the other hand. Interestingly, our results indicate that these two factors, self and relatedness, seem to function as relatively independent mediators. In the context of mother-child relationships, this aspect is 
reflected in the finding that the mediating function of the Relatedness Stance construct did not alter the Self-Representation's mediation effect in the association between Maternal Representation and Problem Behavior. Such a direction of findings suggests that children may take on dysfunctional relatedness patterns independent of underlying levels of self-regard and that internal cognitive-affective schemas of caregivers may affect behavior not only through self-formation processes but also by directly leading to the adoption of maladaptive interpersonal reaction tendencies.

Moreover, while both the Self-Worth and the Relatedness Stance constructs mediated the effect of Maternal Care on the Symptomatology construct (defined by high scores on both factors; Internalizing and Externalizing problems), the separate analysis on Externalizing and Internalizing scores indicated that Self-Worth is a stronger mediator for the effect of Maternal Care on Internalizing problems, while Relatedness Stance is a stronger mediator for the Maternal Care effect on Externalizing problems. This pattern of results may further suggest specificity of the means by which internal representations translate into exhibited behavior; children's representations of the mother are linked with behavioral problems that are more internally directed (Internalizing problems) through their associations with self-representations, while the pathway from children's representations of the mother to more external, interpersonally directed problem behavior (Externalizing problems) passes through their associations with skewed relatedness patterns.

There are some specific limitations that affect the interpretation of the present results. First, we note that in our analyses, we did not control for stability and initial correlations of the study variables, mainly children's representations of the mother, relatedness patterns, and problem behavior. It is therefore difficult to draw conclusions regarding the direction of the effects, and future studies should include a careful examination of the longitudinal hypotheses. Also, replications in other settings in Israel are needed in order to determine whether our findings apply generally to the Israeli context. Second, we evaluated children's representations of the mother and skewed relatedness patterns to mother only; evaluations of the effect of paternal representations as well as relatedness patterns to father and in other interpersonal relationships may add to the proposed model. In addition, researchers should examine the hypothesized interactions between the parent being represented, relatedness patterns to both parents, and specific domains of adjustment. Third, in the present study, we evaluated a latent construct of Relatedness Stance composed of two indicators measuring an excessive tendency toward a dependent or avoidant interaction style. Future research should also emphasize the differential contribution of each of the skewed relatedness patterns to children's adjustment. To the best of our knowledge, for this agegroup, there is a lack of additional measures for specific skewness toward an avoidant or a dependent style. Assuming progress in this area, further studies would benefit from the attempt to represent each of the specific relatedness styles as a latent variable defined as a multimethod, multimeasure. Finally, even though teachers' reports of children's behavior are a reasonable criterion, other assessments of children's behavior and feelings (i.e., sociometric evaluations, direct observations, parent and peer reports) may shed additional light on the implications of the model proposed.

Our results seem to show that consistent experiences of an essentially benevolent and caring maternal object seem to be of central importance for children's regulation of behavior and that relatedness stances and self-worth have interceding effects in this process. These findings might suggest some direction for possible intervening programs and point to the importance of the interplay between interpersonal and intrapersonal factors in child problem behaviors. Within the limits of our study design, our conclusion provides an optimistic base for mother-child dyadic intervention, with school-age children exhibiting problem behavior. The direction of our results seems to indicate that such an intervention, usually employed with younger children (Cohen, Lojkasek, Muir, Muir, \& Parker, 2002), could be relevant for the ongoing construction of benevolent maternal working 
models in middle childhood. Furthermore, developmental research has pointed out that in middle childhood, children learn how to express and regulate behavior not only through interactions with parents but also through interactions with teachers, peers, and others who play a significant role in their lives (Denham, 1998). Accordingly, interventions that enhance real-life interactions fostering the reliance on benevolent others may be helpful for the assimilation and accommodation of positive experiences that might in turn influence the child's existing internal mental representations of others, resulting in increased adjustment capabilities. Such an assumption, of course, deserves further research.

Although our conceptualization and assessment of children's representations of the mother point to a stable core of affective valence that characterizes them, it is important to note that children are active agents constantly shaping their mental experience and their evolving internal world through the transactions with significant and generalized others. Moreover, these transactions are embedded in an extensive web of cultural values and expectations that may indirectly affect children's representations of their mothers beyond particular experiences. It may be the case, for example, that the marked collectivistic and familial values of the Israeli society produce a greater emphasis on the positive qualities of children's maternal representations. In a relatively community-oriented society, such as the one reflected in our study, children's positive and rather even ideal representations of their mothers may contribute to lower levels of problem behavior, while in other cultural contexts, mainly more individualistically oriented ones, more ambivalent or differentiated maternal representations may be linked to less symptomatic behavior (e.g., Besser \& Blatt, 2007; Priel, Besser, Waniel, \& Yonas-Segal, 2007). The complementary influence of ongoing interpersonal experiences in external reality and of cross-cultural differences on changes in children's internal representations, although recognized, is beyond the scope of the present research.

\section{References}

Achenbach, T. M. (1991). Manual for the Teacher's Report Form and 1991 Profile. Burlington: Department of Psychiatry, University of Vermont.

Achenbach T. M., \& Rescorla, L. A. (2001). Manual for the ASEBA School-Age Forms \& Profiles. Burlington: University of Vermont, Research Center for Children, Youth, \& Families.

Ainsworth, M. D. S., Blehar, M. C., Waters, E., \& Wall, S. (1978). Patterns of attachment: A psychological study of the strange situation. Hillsdale, NJ: Erlbaum.

Allen, J. P., Hauser, S. T., Eickholt, C., Bell, K. L., \& O'Connor, T. G. (1994). Autonomy and relatedness in family interactions as predictors of expressions of negative affect. Journal of Research on Adolescence, 4, 535-552.

Anderson, J. C., \& Gerbing, D. W. (1988). Structural equation modeling in practice: A review and recommended two-step approach. Psychological Bulletin, 103, 411-423.

Arbuckle, J. L. (1999). Amos: A structural equation modeling program. Chicago: SmallWaters.

Avery, R. R., \& Ryan, R. M. (1988). Object relations and ego development: Comparison and correlates in middle childhood. Journal of Personality, 56, 547-569.

Baldwin, M. W. (1992). Relational schemas and the processing of social information. Psychological Bulletin, $112,461-484$.

Baldwin, A., Cole, R., \& Baldwin, C. (Eds.), (1982). Parental pathology, family interaction, and the competence of the child in school. Monographs of the Society for Research in Child Development, 47(5, Serial No. 197), 3.

Baron, R. M., \& Kenny, D. A. (1986). The moderatormediator variable distinction in social psychological research: Conceptual, strategic, and statistical considerations. Journal of Personality and Social Psychology, 51, 1173-1182.

Baumeister, R. F. (1990). Suicide as escape from self. Psychological Review, 97, 90-113.

Baumrind, D. (1989). Rearing competent children. In W. Damon (Ed.), Child development today and tomorrow (pp. 349-378). San-Francisco: Jossey-Bass.

Belsky, J., \& Rovine, M. (1987). Temperament and attachment security in the strange situation: An empirical rapprochement. Child Development, 58, 787-795.

Bentler, P. M., \& Bonett, D. G. (1980). Significance tests and goodness of fit in the analysis of covariance structures. Psychological Bulletin, 88, 588-606.

Besser, A., \& Blatt, S. J. (2007). Identity consolidation and internalizing and externalizing problem behaviours in early adolescence. Psychoanalytic Psychology, 24, 126-149.

Blatt, S. J. (2004). Experiences of depression: Theoretical, clinical, and research perspectives. Washington, DC: American Psychological Association.

Blatt, S. J., Auerbach, J. S., \& Levy, K. N. (1997). Mental representations in personality development, psychopathology, and the therapeutic process. Review of General Psychology, 1, 351-374.

Blatt, S. J., Bers, S. A., \& Schaffer, C. E. (1993). The assessment of self descriptions. Unpublished manual, Yale University, New Haven, CT.

Blatt, S. J., Chevron, E. S., Quinlan, D. M., Schaffer, C. E., \& Wein, S. (1992). The assessment of qualitative and 
structural dimensions of object representations (Rev. ed.). Unpublished manual, Yale University, New Haven, CT.

Blatt, S. J., Wein, S. J., Chevron, E., \& Quinlan, D. M. (1979). Parental representations and depression in normal young adults. Journal of Abnormal Psychology, 38, 388-397.

Blatt, S. J., Wiseman, H., Prince-Gibson, E., \& Gatt, C. (1991). Object representations and change in clinical functioning. Psychotherapy, 28, 273-283.

Bowlby, J. (1969). Attachment and loss: Attachment. New York: Basic Books.

Bowlby, J. (1973). Attachment and loss: Separation, anxiety and anger. New York: Basic Books.

Bowlby, J. (1980). Attachment and loss: Loss. New York: Basic Books.

Bretherton, I. (1990). Open communication and internal working models: Their role in the development of attachment relationships. In R. Thompson (Ed.), Nebraska symposium on motivation: Vol. 36. Socioemotional development (pp.39-113). Lincoln: University of Nebraska Press.

Bretherton, I., \& Munholland, K. A. (1999).). Internal working models in attachment relationships: A construct revisited. In J. Cassidy \& P. R. Shaver (Eds.), Handbook of attachment theory, research and clinical applications (pp.89-114). New York: Guilford Press.

Buist, K. L., Dekovilc, M., Meeus, M., \& Van-Aken, M. A. G. (2004). The reciprocal relationship between early adolescent attachment and internalizing and externalizing problem behavior. Journal of Adolescence, 27, 251-266.

Calabrese, M. L., Farber, B. A., \& Westen, D. (2005). The relationship of adult attachment constructs to object relational patterns of representing self and others. Journal of the American Academy of Psychoanalysis and Dynamic Psychiatry, 33, 513-530.

Cassidy, J., \& Berlin, L. J. (1994). The insecure/ambivalent pattern of attachment: Theory and research. Child Development, 65, 971-991.

Cassidy, J., Kirsh, S. J., Scolton, K. S., \& Parke, R. D. (1996). Attachment and representations of peer relationships. Developmental Psychology, 32, 892-904.

Cohen, N. J., Lojkasek, M., Muir, E., Muir, R., \& Parker, C. J. (2002). Six-month follow-up of two motherinfant psychotherapies: Convergence of therapeutic outcomes. Infant Mental Health Journal, 23, 361-380.

Damon, W., \& Hart, D. (1988). Self-understanding in childhood and adolescence. New York: Cambridge University Press.

Denham, S. A. (1998). Emotional development in young children. Guildford Series on Social and Emotional Development, 2, 19-57.

Diamond, D., \& Blatt, S. J. (1994). Internal working models and the representational world in attachment and psychoanalytic theories. In M. B. Sperling \& W. H. Berman (Eds.), Attachment in adults: Clinical and developmental perspectives (pp. 72-97). New York: Guilford Press.

Finnegan, R. A., Hodges, E. V. E., \& Perry, D. G. (1996). Preoccupied and avoidant coping during middle childhood. Child Development, 67, 1318-1328.

Fonagy, P. (1994). Mental representations from an intergenerational cognitive science perspective. Infant Mental Health Journal, 15, 57-68.

Fonagy, P., \& Target, M. (1997). Attachment and reflective function: Their role in self organization. Development and Psychopathology, 9, 679-700.
Fox, N. A., Kimmerly, N. L., \& Schafer, W. D. (1991). Attachment to mother/attachment to father: A metaanalysis. Child Development, 62, 210-225.

Frank, S. J., Pirsch, L. A., \& Wright, V. C. (1990). Late adolescents' perceptions of their relationships with their parents: Relationships among de-idealization, autonomy, relatedness, and insecurity, and implications for adolescent adjustment and ego identity status. Journal of Youth and Adolescence, 19, 571-589.

Goldberg, S., Muir, R., \& Kerr, S. (1995). Attachment theory as a secure base for psychoanalytic exploration: A review of attachment theory: Social, developmental, and clinical perspectives. Hillsdale, NJ: Analytic Press.

Greenberg, J. R., \& Mitchell, S. A. (1983). Object relations in psychoanalytic theory. Cambridge, MA: Harvard University Press.

Gruen, R. J., \& Blatt, S. J. (1990). Change in self and object representations during long-term dynamically oriented treatment. Psychoanalytic Psychology, 7, 399-422.

Hamilton, C. E. (2000). Continuity and discontinuity of attachment from infancy through adolescence. Child Development, 71, 690-694.

Harter, S. (1986). Processes underlying the construction, maintenance, and enhancement of the self-concept in children. In J. Suls \& A. G. Greenwald (Eds.), Psychological perspectives on the self (Vol. 4, pp. 137-181). Hillsdale, NJ: Lawrence Erlbaum.

Hodges, V. E., Finnegan, R. A., \& Perry, D. (1999). Skewed autonomy-relatedness in preadolescents' conceptions of their relationship with mother, father and best friend. Developmental Psychology, 35, 737-748.

Hoyle, R. H. (1995). Structural equation modeling: Concepts, issues, and applications. Thousand Oaks, CA: Sage.

Kelloway, E. K. (1998). Using LISREL for structural equation modeling: A researcher's guide. Newbury Park, CA: Sage.

King, C. A., Naylor, M. W., Segal, H. G., Evans, T., \& Shain, B. N. (1993). Global self-worth, specific selfperceptions of competence, and depression in adolescents. Journal of the American Academy of Child and Adolescent Psychiatry, 32, 745-752.

Landry, S. H., Smith, K. E., Swank, P. R., \& MillerLoncar, C. L. (2000). Early maternal and child influences on children's later independent cognitive and social functioning. Child Development, 71, 358-375.

Levy, K. N., Blatt, S. J., \& Shaver, P. R. (1998). Attachment styles and parental representations. Journal of Personality and Social Psychology, 74, 407-419.

Lyons-Ruth, K., Connel, D. B., Gruneubaum, H. U., \& Botein, S. (1990). Infants at social risk: Maternal depression and family support services as mediators of infant development and security of attachment. Child Development, 61, 85-98.

MacKinnon, D. P., Lockwood, C. M., Hoffman, J. M., West, S. G., \& Sheets, V. (2002). A comparison of methods to test mediation and other intervening variable effects. Psychological Methods, 7, 83-104.

Main, M. (1994). Discourse, prediction, and studies in attachment: Implications for psychoanalysis. Journal of the Psychoanalytic Association, 41S, 209-244.

Main, M., Kaplan, N., \& Cassidy, J. (1985). Security in infancy, childhood and adulthood: A move to the level of representation. In I. Bretherton \& E. Waters (Eds.), Growing points in attachment: Theory and research. 
Monographs of the Society for Research in Child Development (Serial No. 209), 66-104.

Mallinckrodt, B., Abraham, W. T., Wei, M., \& Russell, D. W. (2006). Advances in testing the statistical significance of mediation effects. Journal of Counseling Psychology, 53, 371-378.

Piaget, J. (1955). The language and thought of the child. New York: Hartcourt Brace.

Piaget, J. (1962). Play, dreams, and imitation in childhood. New York: Norton.

Pietromonaco, P. R., \& Feldman-Barett, L. (2000). The internal working models concepts: What do we really know about the self in relation to others? Review of General Psychology, 4, 155-175.

Priel, B., \& Besser, A. (2001). Bridging the gap between attachment and object relations theories: A study of the transition to motherhood. British Journal of Medical Psychology, 74, 85-100.

Priel, B., Besser, A., Waniel, A., \& Yonas-Segal, M. (2007). Interpersonal and intrapersonal processes in the formation of maternal representations in middle childhood: Review, new findings and future directions. Israeli Journal of Psychiatry and Related Sciences, 44, 255-265.

Priel, B., Kantor, B., \& Besser, A. (2000). Two maternal representations: A study of Israeli adopted children. Psychoanalytic Psychology, 17, 128-145.

Priel, B., Myodovnick, E., \& Rivlin-Beniaminy, N. (1995). Parental representations among preschool and fourth-grade children: Integrating object relational and cognitive developmental frameworks. Journal of Personality Assessment, 65, 372-388.

Priel, B., Waniel, A., Yones, M., Seksig-Bitton, I., Weinberg, B., \& Zerach, G. (2003). Manual for the coding of self representations among children [Hebrew]. Unpublished manuscript, Behavioral Sciences Department, Ben-Gurion University of the Negev, BeerSheva, Israel.

Rubin, K. H., Bukowski, W., \& Parker, J. G. (1998). Peer interactions, relationships, and groups. In N. Eisenberg (Ed.), Handbook of child psychology: Vol. 3. Social, emotional, and personality development (pp. 619700). New York: Wiley.

Ryan, R. M., Stiller, J. D., \& Lynch, J. H. (1994). Representations of relationships to teachers, parents, and friends as predictors of academic motivation and selfesteem. Journal of Early Adolescence, 14, 226-249.

Schneider, B. H., Atkinson, L., \& Tardif, C. (2001). Parentchild attachment and children's peer relations: A quantitative review. Developmental Psychology, 37, 86-100.

Segal, H. G., Westen, D., Lohr, N. E., \& Silk, K. R. (1993). Clinical assessment of object relations and social cognition using stories told to the picture arrangement subtest of the WAIS-R. Journal of Personality Assessment, 61, 58-80.

Segal, Z. V., \& Blatt, S. J. (Eds.). (1993). The self in emotional distress: Cognitive and psychodynamic perspectives. New York: Guilford Press.

Shields, A., Ryan, R. M., \& Cicchetti, D. (2001). Narrative representations of caregivers and emotion disregulation as predictors of maltreated children's rejection by peers. Developmental Psychology, 37, 321-337.

Shrout, P. E., \& Bolger, N. (2002). Mediation in experimental and nonexperimental studies: New procedures and recommendations. Psychological Methods, 7, 422-445.

Shrout, P. E., \& Fleiss, J. L. (1979). Intraclass correlations: Uses in assessing rater reliability. Psychological Bulletin, 86, 420-428.

Slade, A., \& Aber, J. L. (1992). Attachment, drives and development: Conflicts and convergences in theory. In J. W. Baron, N. M. Eagle, \& D. L. Wolitzky (Eds.), Interface of psychoanalysis and psychology (pp. 154-185). Washington, DC: American Psychological Association.

Sobel, M. E. (1982). Asymptotic confidence intervals for indirect effects in structural equation models. In $\mathrm{S}$. Leinhardt (Ed.), Sociological methodology 1982 (pp. 290-312). Washington, DC: American Sociological Association.

Steele, H., Steele, M., \& Fonagy, P. (1996). Associations among attachment classifications of mothers, fathers, and their infants. Child Development, 67, 541-555.

Toth, S. L., \& Cicchetti, D. (1996). Patterns of relatedness, depressive symptomatology, and perceived competence in maltreated children. Journal of Consulting and Clinical Psychology, 64, 32-41.

van IJzendoorn, M. H., \& De Wolff, M. S. (1997). In search of the absent father-meta-analyses of infantfather attachment: A rejoinder to our discussants. Child Development, 68, 604-609.

Waniel, A., Besser, A., \& Priel, B. (2006). Mother and self-representations: Investigating associations with symptomatic behavior and academic competence in middle childhood. Journal of Personality, 74, 223-266.

Werner, H. (1948). Comparative psychology of mental development. New York: International University Press.

Westen, D., Klepsen, J., Ruffins, S. A., Silverman, M., Lifton, N., \& Boekamp, J. (1991). Object relations in childhood and adolescence: The development of working representations. Journal of Consulting and Clinical Psychology, 59, 400-409.

Zilber, N., Auerbach, J., \& Lerner, Y. (1994). Israeli norms for the Achenbach Child Behavior Checklist: Comparison of clinically-referred and non-referred children. Israeli Journal of Psychiatry and Related Disciplines, $31,5-12$ 